\title{
Nucleus Accumbens Functional Connectivity with the Frontoparietal Network Predicts Subsequent Change in Body Mass Index for American Children
}

\author{
Shervin Assari $1,2, * \mathbb{C}$, Shanika Boyce ${ }^{3}$ and Mohsen Bazargan ${ }^{1,4}$ \\ 1 Department of Family Medicine, Charles Drew University, Los Angeles, CA 90059, USA; \\ mohsenbazargan@cdrewu.edu \\ 2 Department of Urban Public Health, Charles Drew University, Los Angeles, CA 90059, USA \\ 3 Department of Pediatrics, Charles Drew University, Los Angeles, CA 90059, USA; shanikaboyce@cdrewu.edu \\ 4 Department of Family Medicine, University of California Los Angeles (UCLA), Los Angeles, CA 90095, USA \\ * Correspondence: assari@umich.edu; Tel.: +(734)-232-0445; Fax: +734-615-8739
}

Received: 10 August 2020; Accepted: 2 October 2020; Published: 3 October 2020

check for updates

\begin{abstract}
Background: Nucleus accumbens (NAc) is a brain structure with a well-established role in the brain reward processing system. Altered function of the NAc is shown to have a role in the development of food addiction and obesity. However, less is known about sex differences in the role of NAc function as a predictor of children's change in body mass index (BMI) over time. Aim: We used the Adolescent Brain Cognitive Development data (version 2.01) to investigate sex differences in the predictive role of the NAc functional connectivity with the frontoparietal network on children's BMI change over a one-year follow-up period. Methods: This 1-year longitudinal study successfully followed 3784 9-10-year-old children. Regression models were used to analyze the data. The predictor variable was NAc functional connectivity with the frontoparietal network measured using resting-state functional magnetic resonance imaging (fMRI). The primary outcome was BMI at the end of the 1-year follow up. Covariates included race, ethnicity, age, socioeconomic factors, and baseline BMI. Sex was the effect modifier. Results: NAc functional connectivity with the frontoparietal network was predictive of BMI changes over time. This association remained significant above and beyond all covariates. The above association, however, was only significant in female, not male children. Conclusion: The epidemiological observation that NAc functional connectivity is associated with BMI changes in children is an extension of well-controlled laboratory studies that have established the role of the NAc in the brain reward processing. More research is needed on sex differences in the brain regions that contribute to childhood obesity.
\end{abstract}

Keywords: children; obesity; nucleus accumbens; body mass index; frontoparietal

\section{Introduction}

Nucleus accumbens (NAc), a central region in the basal ganglia, has a significant role in Pavlovian learning [1-6]. NAc is involved in regulation of incentive salience, pleasure-seeking, reward dependence, and positive reinforcement [7-12]. As such, altered NAc function is central to food, tobacco, alcohol, and drug-seeking behaviors [13-17]. By regulating the response to food cues, the NAc also plays a unique role in pathogenesis of food addiction, eating disorders, [1,18-20], obesity, and high body mass index (BMI) [21].

The NAc mediates cue-triggered reward-seeking behaviors [9,18,22-24]. In animal models [25] and humans [26-31], the obesity-prone differ from the obesity-resistant in NAc activity. Due to its central role in incentive motivation, the NAc is involved in the expression of behaviors that contribute to the development of obesity [25]. Food cues are shown to elicit a robust NAc dopamine response at the time 
of hunger [21]. Thus, dopamine release in the NAc alters how an individual seeks food [17,29,32-34]. Activity in the NAc is particularly enhanced in obesity-susceptible people [25]. Although we know that NAc has a prominent role in the development of obesity, most of the existing evidence is limited to animal studies, small-sized human studies in a highly controlled laboratory settings, or cross-sectional studies [26-31]. As such, we know little about the role of the NAc in shaping future risk of obesity in the general population.

The NAc, however, does not perform its functions in a vacuum as it receives projections from a plethora of brain regions and networks. Among the various brain networks that work with the basal ganglia, striatum, and NAc is the frontoparietal network [35]. Such a connectivity is linked to food preference [36], obesity [37-41], and eating disorders [42,43]. Via frontoparietal-accumbal connectivity, frontoparietal network and NAc joint function is involved in motivated behavior, food seeking, emotion regulation, and obesity [37-41]. It has also shown that NAc functional connectivity with frontoparietal-accumbal may have some role in dopaminergic and reward systems of the brain [44]. As a result, the functional connectivity of the frontoparietal network and the NAc may have a role as a predictor factor for the BMI at baseline and change over time [37-41].

Aims

Although NAc function is a well-established predictor of food-seeking behaviors [21], less is known about the role of connectivity between the NAc and frontoparietal network on obesity [37-41]. While we know that NAc function is different in obesity-prone individuals than others [26-31], there is a need for longitudinal epidemiological studies on the NAc-frontoparietal connectivity as a predictor of obesity risk at the population level [21]. This is important because individuals are also under the influence of their social context and environment, which can also predict BMI changes. In addition, even less is known about sex differences in the role that functional connectivity between the NAc and frontoparietal network has in predicting children's BMI change over time. To respond to this gap in the literature, we conducted an epidemiological study of 9-10-year-old children in the U.S. to test if NAc functional connectivity with the frontoparietal network at baseline is associated with future BMI change over a one-year period. Our second aim was to test sex differences in the above association.

\section{Materials and Methods}

\subsection{Design and Settings}

A secondary analysis was performed with a cross-sectional design. We used data from the Adolescent Brain Cognitive Development (ABCD) study [45-49]. ABCD, a landmark study of brain development from childhood to emerging adults, is unique in the United States. Although details of the ABCD methods, measures, design, sample, and sampling are described elsewhere [45,50], we briefly review them.

\subsection{Participants and Sampling}

In the $A B C D$, we only included children who were between the ages of 9 and 10 years. The ABCD children were enrolled from multiple cities across the United States. Overall, children were recruited to the $A B C D$ study from 21 sites. The primary strategy for sampling in the ABCD study was the school systems [51]. In the current analysis, 3784 participants entered. Our analysis' eligibility for inclusion was 9-10-year-old non-twin participants who had data on the baseline and follow up BMI at the end of the first year. Participants could be from any race or ethnicity.

\subsection{Neuroimaging Data Have Been Processed}

We used neuroimaging data which were already processed. The ABCD Magnetic Resonance Imaging (MRI) data include functional and structural MRI. Functional MRI (fMRI) includes resting-state and task-based fMRI. Resting-state fMRI was used for this analysis. Beta correlation between the 
frontoparietal network and the automatic subcortical segmentation (ASEG) region of interest (ROI) right-accumbens area was calculated. Tesla 1 (T1) and T2 weighted fMRI and sMRI images were taken using a 3 tesla (T) Siemens Prisma (Erlangen, Germany), General Electric 750 (Chicago, IL, USA), and Phillips (Amsterdam, The Netherlands) multi-channel coiled scanners, all capable of multiband echo-planar imaging (EPI) acquisitions. A localizer was implemented at the beginning of each scan, followed by a T1 weighted fMRI image acquisition. Functional T2 weighted scans were then acquired at rest and then throughout three psychological tasks. A large-scale multimodal data acquisition allowed the ABCD study to collect an unprecedented set of images on a large number of adolescents that were selected and enrolled via 21 data acquisition sites across various U.S. states. As mentioned above, both $A B C D$ structural and functional MRI data are processed and the tabulated regions of interest (ROI) data were downloaded from the National Institute of Health (NIH) Data Archive (NDA). $\mathrm{ABCD}$ imaging data were limited to resting-state fMRI. More information on the imaging protocols are available here [52-54].

\subsection{Study Variables}

\subsubsection{Outcome}

Body Mass Index (BMI). The children's BMI at baseline and at the end of the 1-year follow-up was calculated based on participants' measured height and weight. Height was measured three times in inches. The weight of the child was measured up to three times in pounds. BMI was treated as a continuous measure. Although some research has used percentile BMI related to age and sex norms, we used raw BMI because the analyses broke the sample by sex and the age range of the participants was very narrow (only 9- and 10-year-old children). Other research has also used BMI rather than percentile BMI related to age and sex norm.

\subsubsection{Independent Variable}

NAc. Using resting-state fMRI, NAc was defined as the average correlation between the frontoparietal network and ASEG ROI right-accumbens area. This is functional connectivity between the frontoparietal network and the NAc. The resting-state fMRI was measured at baseline at the same time that socioeconomic status (SES) indicators and baseline BMI were measured.

\subsubsection{Confounders}

Race. Race, a self-identified variable, was two binary variables: Blacks, other races, and Whites (reference category).

Ethnicity. Ethnicity, a self-identified variable, was 1 for Hispanics and 0 for non-Hispanics (reference category).

Sex. A dichotomous variable, sex was coded as below: males $=1$, females $=0$.

Age. Age (months), calculated as the difference between birth and the time of enrollment to the study, measured in months, was reported by parents.

Parent education (y). Parents reported their years of schooling. This variable was operationalized as a continuous (interval) variable ranging from 0 for no formal education to 21 for doctoral degrees.

Parent employment. Parents reported their employment. This variable was operationalized as a categorical variable with 0 for non-employed and 1 for employed.

Family income. Family income was a 1-10 interval measure where a higher score indicated higher income. The total combined family income in the past 12 months was asked. Responses were $1=$ less than USD 5000; $2=$ USD 5000; $3=$ USD 12,000; $4=$ USD 16,000; $5=$ USD 25,000; 6 = USD 35,000; $7=$ USD 50,000; 8 = USD 75,000; 9 = USD 100,000; $10=$ USD 200,000. 


\subsection{Main Data Analysis}

The statistical package, SPSS 22.0 (IBM, Armonk, NY, USA), was applied for data analysis. Mean (standard deviation; SD) and frequency (relative frequency; \%) was used to describe all the study variables. We also used the Pearson correlation test for bivariate analysis of the associations between the study variables. For multivariable modeling, we ran four regression models. To do so, first we tested the assumptions that are required for running a regression model. BMI time 1 and time 2 had a near to normal distribution. There is no collinearity between the study variables. In our model, the NAc functional connectivity with the frontoparietal network was used as the independent variable (predictor), baseline BMI and demographic and SES indicators as the covariates and follow-up BMI as the outcome. Our 1st two models were performed in the pooled sample. Our 1st model was without (Model 1), and our 2nd model was with (Model 2) an interaction term between sex and NAc functional connectivity with the frontoparietal network. Our next models were run for females (Model 3) and males (Model 4). Models were identical for right and left NAc. All models were statistically significant at a 0.001 and explained more than $20 \%$ of the variance of the outcome, mainly because the outcome and independent variable (predictor) had a strong correlation (baseline and time $2 \mathrm{BMI}$ ). This information is added to the statistical analysis section of the paper. We did not adjust the BMIs based on the age and sex of the participants because the BMI values of each individual were being compared at two time points (baseline and follow up BMI). As every individual is compared to his/herself, there is no need to adjust based on the distribution of BMI in the population. There are several studies that have used the same approach and have not adjusted based on norms. Unstandardized coefficient (b), standard error (SE), $95 \%$ confidence interval (95\% CI), and $p$-value were reported for our model. A $p$-value equal or less 0.05 was significant.

\subsection{Sensitivity Analysis}

In our main analysis, the outcome was BMI time 2, while BMI time 1 and all covariates were controlled. We ran a mixed effects model with BMI time 1 as the outcome. The argument behind this approach if the result of our main analysis with BMI time 2 is robust is that we should test the same interaction in our replication model, despite the sample size and the temporal aspects of the measures having changed. As our findings show, our sensitivity analysis replicated the same interaction between sex and NAc functional connectivity with the frontoparietal network on BMI (Appendix A Tables and Figures).

\subsection{Ethics}

The ABCD study protocol received Institutional Review Board (IRB) approval from several institutions, including but not limited to the University of California, San Diego (UCSD). All participating children provided assent. All participating parents signed informed consent [50]. As we only performed a secondary analysis of fully de-identified data, our study was non-human subject research. Thus, our analysis and report did not require an IRB review (exempt from a full IRB review).

\section{Results}

\subsection{Descriptives}

A total number of 3784, 9-10-year-old children were analyzed. Participants were 1953 male and 1831 female children. Table 1 presents a summary of the descriptive statistics for the children overall and by sex. 
Table 1. Data overall $(n=3784)$.

\begin{tabular}{|c|c|c|c|c|c|c|}
\hline & \multicolumn{2}{|c|}{ All } & \multicolumn{2}{|c|}{ Female } & \multicolumn{2}{|c|}{ Male } \\
\hline & $\mathbf{n}$ & $\%$ & $\mathrm{n}$ & $\%$ & $\mathrm{n}$ & $\%$ \\
\hline \multicolumn{7}{|l|}{ Sex } \\
\hline Female & 1831 & 48.4 & 1831 & 100.0 & - & - \\
\hline Male & 1953 & 51.6 & - & - & 1953 & 100.0 \\
\hline \multicolumn{7}{|l|}{ Age } \\
\hline 9 & 1811 & 47.9 & 902 & 49.3 & 909 & 46.7 \\
\hline 10 & 1966 & 52.1 & 927 & 50.7 & 1039 & 53.3 \\
\hline \multicolumn{7}{|l|}{ Child ethnicity } \\
\hline Non-Hispanic & 3015 & 79.7 & 1464 & 80.0 & 1551 & 79.4 \\
\hline Hispanic & 769 & 20.3 & 367 & 20.0 & 402 & 20.6 \\
\hline \multicolumn{7}{|l|}{ Child race } \\
\hline White & 2914 & 77.0 & 1382 & 75.5 & 1532 & 78.4 \\
\hline Other & 334 & 8.8 & 176 & 9.6 & 158 & 8.1 \\
\hline Black & 536 & 14.2 & 273 & 14.9 & 263 & 13.5 \\
\hline \multicolumn{7}{|l|}{ Parental employment } \\
\hline No & 1153 & 30.5 & 545 & 29.8 & 608 & 31.1 \\
\hline Yes & 2631 & 69.5 & 1286 & 70.2 & 1345 & 68.9 \\
\hline \multicolumn{7}{|l|}{ Parents married } \\
\hline No & 1049 & 27.7 & 510 & 27.9 & 539 & 27.6 \\
\hline \multirow[t]{2}{*}{ Yes } & 2735 & 72.3 & 1321 & 72.1 & 1414 & 72.4 \\
\hline & Mean & SD & Mean & SD & Mean & SD \\
\hline Parent education (y) & 16.89 & 2.63 & 16.96 & 2.59 & 16.82 & 2.66 \\
\hline Family income (1-10) & 7.51 & 2.17 & 7.56 & 2.12 & 7.46 & 2.22 \\
\hline BMI (baseline) & 18.53 & 3.93 & 18.59 & 4.03 & 18.48 & 3.84 \\
\hline BMI $(1 \mathrm{y})$ * & 20.10 & 3.7. & 20.88 & 5.37 & 19.37 & 4.43 \\
\hline $\begin{array}{l}\text { Right NAc functional connectivity with } \\
\text { the frontoparietal network }\end{array}$ & -0.01 & 0.15 & -0.01 & 0.14 & -0.01 & 0.16 \\
\hline $\begin{array}{l}\text { Left NAc functional connectivity with } \\
\text { the frontoparietal network }\end{array}$ & -0.05 & 0.17 & -0.06 & 0.16 & -0.05 & 0.17 \\
\hline
\end{tabular}

Nucleus accumbens (NAc): average correlation between frontoparietal network and right- and left-accumbens area; $\mathrm{SD}=$ standard deviation, $\mathrm{BMI}=$ body mass index. ${ }^{*} p<0.05$ for a comparison of males and females.

\subsection{Bivariate Correlations}

Table 2 shows a summary of bivariate correlations. Functional connectivity between the frontoparietal network and the NAc was inversely correlated with follow-up BMI. The bivariate correlation between right and left functional connectivity between NAc and frontoparietal network was almost zero. Although baseline BMI was not associated with right and left functional connectivity between the NAc and frontoparietal network, follow-up BMI was correlated with right and left functional connectivity between the NAc and frontoparietal network. Baseline and follow-up BMI were positively correlated; however, this correlation was not very strong. From various SES indicators, parental marital status and parental education were correlated with right but not left functional connectivity between the NAc and frontoparietal network.

\subsection{Multivariate Analysis}

Table 3 shows a summary of the results of two regression models in the pooled sample. These models show a significant and negative effect of NAc functional connectivity with the frontoparietal network on follow-up BMI in children. This means a higher beta coefficient that reflected higher NAc functional connectivity with the frontoparietal network was associated with lower BMI gain over time. Results were identical for right and left NAc. 
Table 2. Correlations in the total sample.

\begin{tabular}{|c|c|c|c|c|c|c|c|c|c|c|c|c|c|}
\hline & 1 & 2 & 3 & 4 & 5 & 6 & 7 & 8 & 9 & 10 & 11 & 12 & 13 \\
\hline 1. Sex (Male) & 1 & 0.03 & -0.03 & -0.02 & 0.01 & 0.00 & -0.02 & -0.03 & -0.02 & -0.01 & -0.02 & -0.02 & $0.03 *$ \\
\hline 2. Age $(10 \mathrm{y})$ & & 1 & 0.01 & 0.01 & -0.01 & 0.00 & 0.02 & $0.04 *$ & $0.05^{* *}$ & $0.09^{* *}$ & -0.01 & 0.00 & -0.01 \\
\hline 3. Race (Black) & & & 1 & $-0.13^{* *}$ & $0.27^{* *}$ & $-0.08^{* *}$ & $-0.04 *$ & $-0.17^{* *}$ & $-0.15^{* *}$ & $0.05^{* *}$ & 0.00 & -0.03 & -0.02 \\
\hline 5. Ethnicity (Hispanic) & & & & & 1 & $-0.15^{* *}$ & $-0.07^{* *}$ & $-0.37^{* *}$ & $-0.31 * *$ & $0.18^{* *}$ & 0.01 & -0.01 & 0.00 \\
\hline 6. Parents married & & & & & & 1 & 0.02 & $0.29 * *$ & $0.49 * *$ & $-0.15^{* *}$ & $-0.05^{* *}$ & $0.05^{* *}$ & -0.03 \\
\hline 7. Parents employed & & & & & & & 1 & $0.23^{* *}$ & $0.23^{* *}$ & -0.01 & 0.01 & 0.02 & 0.03 \\
\hline 10. BMI (baseline) & & & & & & & & & & 1 & $0.10 * *$ & -0.03 & 0.00 \\
\hline 11. BMI (1 y) & & & & & & & & & & & 1 & $-0.04 * *$ & $-0.06^{* *}$ \\
\hline 12. Right NAC & & & & & & & & & & & & 1 & 0.00 \\
\hline 13. Left NAc & & & & & & & & & & & & & 1 \\
\hline
\end{tabular}

NAc: average correlation between the frontoparietal network and ASEG ROI right- and left-accumbens area; $\mathrm{BMI}=$ body mass index; ${ }^{*} p<0.05 ;{ }^{* *} p<0.01$.

Table 3. Overall regression models.

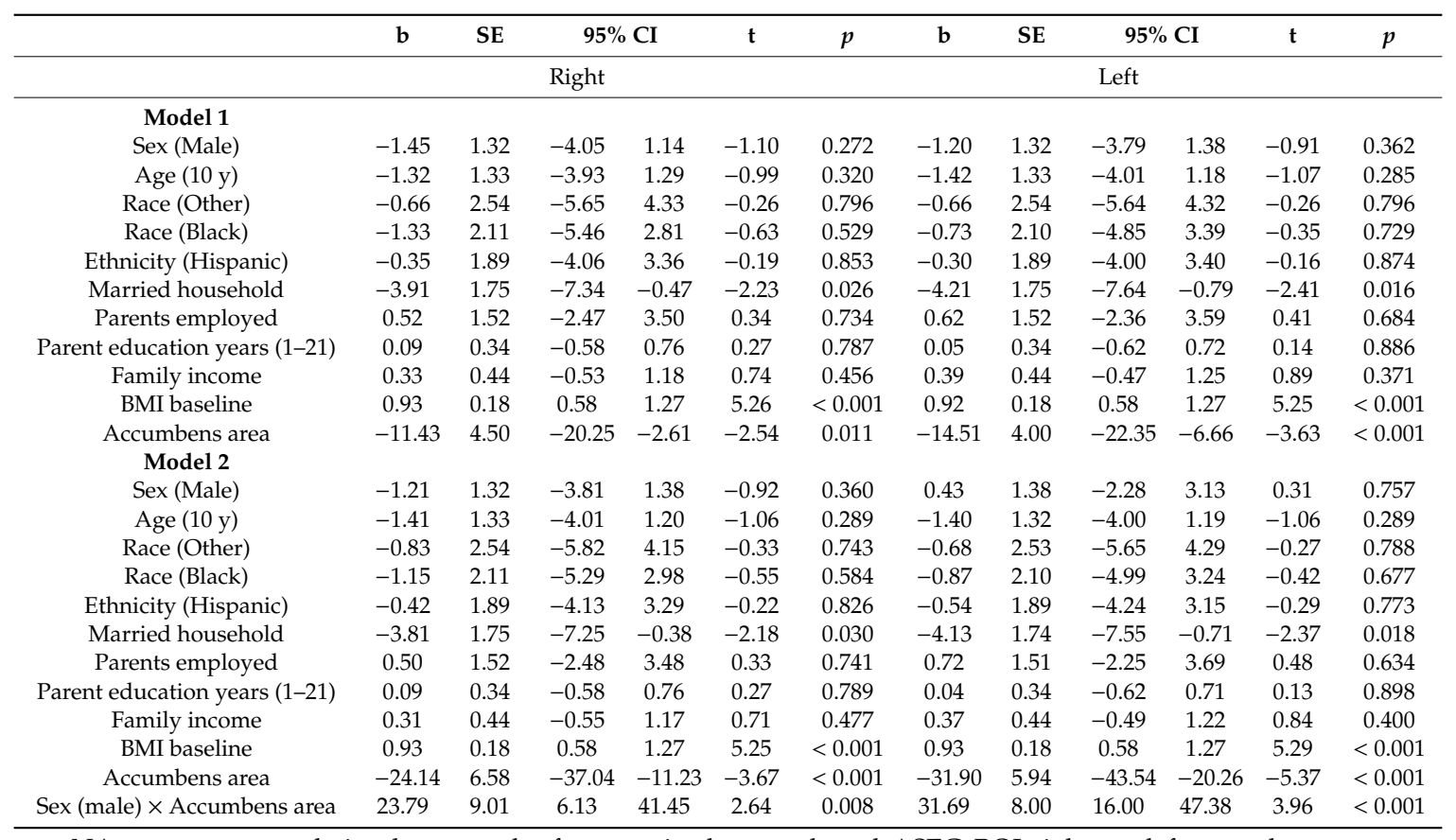

NAc: average correlation between the frontoparietal network and ASEG ROI right- or left-accumbens area (rsfmri_cor_ngd_fopa_scs_aarh or rsfmri_cor_ngd_fopa_scs_aalh); Outcome: BMI at the end of follow up; unstandardized regression coefficient: $b$; statistic: $t$; standard error: $\mathrm{SE}$; confidence interval: $\mathrm{CI}$; $\mathrm{BMI}=$ body mass index.

\subsection{Multivariate Analysis}

Table 4 shows a summary of the results of two regression models in female and male children. These models show a significant and negative effect of NAc functional connectivity with the frontoparietal network on follow-up BMI in females $(b=-23.93 ; p=0.012$ for right and $b=-32.31$; $p=0.000$ for left NAc functional connectivity with the frontoparietal network) but not males ( $b=-0.41$; $p=0.227$ for right and $\mathrm{b}=0.15 ; p=0.621$ for left NAc functional connectivity with the frontoparietal network). Results were identical for right and left NAc. BMI baseline was also positively and significantly associated with time $2 \mathrm{BMI}$, which is reflective of autoregressive correlation $(b=0.90$ for females and 0.98 for males).

\subsection{Sensitivity Analysis}

As the appendix shows, we ran a full series of sensitivity analyses to test if we could successfully replicate the results of our main analysis. As shown above, our main analysis shows that the effect of NAc functional connectivity with the frontoparietal network on BMI time 2, while covariates 
and BMI time 1 was controlled. We ran a mixed effects model with BMI time 1 as the outcome. The argument behind this approach is if the result of our main analysis with BMI time 2 is robust, then we should test the same interaction in our replication model, despite the sample size and the temporal aspects of the measures having changed. As our findings show, our sensitivity analysis replicated the same interaction between sex and NAc functional connectivity with the frontoparietal network on BMI (Appendix A Tables and Figures). That means that not only does the effect of NAc functional connectivity with the frontoparietal network on future BMI depend on sex, but the cross-sectional association between NAc functional connectivity with the frontoparietal network and BMI also statistically differs between male and female children.

Table 4. Sex-specific regression models.

\begin{tabular}{|c|c|c|c|c|c|c|c|c|c|c|c|c|}
\hline & $\mathbf{b}$ & $\mathrm{SE}$ & \multicolumn{2}{|c|}{$95 \%$ CI } & $t$ & $p$ & B & SE & \multicolumn{2}{|c|}{$95 \%$ CI } & $t$ & $P$ \\
\hline & \multicolumn{5}{|c|}{ Right } & \multicolumn{7}{|c|}{ Left } \\
\hline Model 3 & & & & & & & & & & & & \\
\hline Age (10 y) & -2.97 & 2.75 & -8.37 & 2.43 & -1.08 & 0.281 & -2.98 & 2.74 & -8.36 & 2.39 & -1.09 & 0.276 \\
\hline Race (Other) & -1.39 & 5.04 & -11.28 & 8.50 & -0.28 & 0.783 & -1.12 & 5.02 & -10.97 & 8.73 & -0.22 & 0.823 \\
\hline Race (Black) & -2.39 & 4.25 & -10.72 & 5.93 & -0.56 & 0.573 & -1.90 & 4.23 & -10.20 & 6.40 & -0.45 & 0.654 \\
\hline Ethnicity (Hispanic) & -1.39 & 3.95 & -9.14 & 6.35 & -0.35 & 0.724 & -1.72 & 3.94 & -9.44 & 6.00 & -0.44 & 0.662 \\
\hline Married household & -7.74 & 3.58 & -14.78 & -0.71 & -2.16 & 0.031 & -8.39 & 3.57 & -15.38 & -1.39 & -2.35 & 0.019 \\
\hline Parents employed & 0.96 & 3.16 & -5.25 & 7.17 & 0.30 & 0.762 & 1.45 & 3.16 & -4.75 & 7.64 & 0.46 & 0.647 \\
\hline Parent education years (1-21) & 0.20 & 0.72 & -1.21 & 1.62 & 0.28 & 0.779 & 0.10 & 0.72 & -1.31 & 1.51 & 0.14 & 0.891 \\
\hline Family income & 0.73 & 0.90 & -1.03 & 2.49 & 0.82 & 0.415 & 0.84 & 0.89 & -0.91 & 2.60 & 0.94 & 0.345 \\
\hline BMI baseline & 0.90 & 0.36 & 0.20 & 1.59 & 2.51 & 0.012 & 0.90 & 0.36 & 0.20 & 1.60 & 2.53 & 0.012 \\
\hline $\begin{array}{c}\text { Accumbens area } \\
\text { Model } 4\end{array}$ & -23.93 & 9.48 & -42.52 & -5.33 & -2.52 & 0.012 & -32.31 & 8.55 & -49.07 & -15.55 & -3.78 & $<0.001$ \\
\hline Age $(10 y)$ & -0.06 & 0.10 & -0.26 & 0.14 & -0.54 & 0.586 & -0.05 & 0.10 & -0.25 & 0.15 & -0.49 & 0.626 \\
\hline Race (Other) & -0.06 & 0.20 & -0.46 & 0.34 & -0.30 & 0.765 & -0.06 & 0.20 & -0.46 & 0.34 & -0.29 & 0.771 \\
\hline Race (Black) & 0.18 & 0.17 & -0.15 & 0.50 & 1.07 & 0.284 & 0.19 & 0.17 & -0.13 & 0.52 & 1.15 & 0.250 \\
\hline Ethnicity (Hispanic) & 0.19 & 0.14 & -0.09 & 0.47 & 1.32 & 0.189 & 0.18 & 0.14 & -0.10 & 0.47 & 1.27 & 0.203 \\
\hline Married household & -0.07 & 0.14 & -0.34 & 0.20 & -0.50 & 0.614 & -0.07 & 0.14 & -0.34 & 0.19 & -0.54 & 0.586 \\
\hline Parents employed & 0.11 & 0.12 & -0.11 & 0.34 & 0.98 & 0.325 & 0.10 & 0.12 & -0.12 & 0.33 & 0.89 & 0.372 \\
\hline Parent education years $(1-21)$ & -0.02 & 0.03 & -0.07 & 0.03 & -0.86 & 0.391 & -0.02 & 0.03 & -0.07 & 0.03 & -0.85 & 0.396 \\
\hline Family income & -0.05 & 0.03 & -0.11 & 0.02 & -1.37 & 0.170 & -0.05 & 0.03 & -0.11 & 0.02 & -1.41 & 0.159 \\
\hline BMI baseline & 0.98 & 0.01 & 0.96 & 1.01 & 70.80 & $<0.001$ & 0.98 & 0.01 & 0.96 & 1.01 & 70.85 & $<0.001$ \\
\hline Accumbens area & -0.41 & 0.34 & -1.08 & 0.26 & -1.21 & 0.227 & 0.15 & 0.30 & -0.44 & 0.73 & 0.49 & 0.621 \\
\hline
\end{tabular}

\section{Discussion}

Our first main finding suggested that the NAc functional connectivity with the frontoparietal network was associated with 1-year BMI among 9-10-year-old American children. According to our second main finding, this predictive role was true for female children, but not male children. We also replicated these main results by cross-sectional association between NAc functional connectivity with the frontoparietal network and BMI, which also differed by sex. Another source of confidence in our results was that the findings were identical for right and left NAc.

Our first main finding is supported by the lab-based observations that the basal ganglia (striatum and NAc) and frontoparietal network function together [35], and that their functional connectivity is also linked to food preference [36], obesity [37-41], and eating disorders [42,43]. An extensive body of laboratory research has shown that the NAc shell receives dopaminergic inputs from various structures due to various sensory inputs including those related to food [26,55-60]. The NAc is involved in the regulation of feeding, eating, and food seeking behaviors $[1,7,8,20,24,55,61]$. Gamma-aminobutyric acid-A $\left(\mathrm{GABA}_{\mathrm{A}}\right)$ receptors (a receptor for the GABA hormone released by the brain to regulate dopamine levels in its reward pathways) in the NAc shell mediate hyperphagia, overeating, and associated weight gain [62]. NAc controls appetite as well [63]. Motivational responses to food are mediated in part by NAc $\alpha$-amino-3-hydroxy-5-methyl-4-isoxazolepropionic acid (AMPA) receptor transmission [64]. NAc medium spiny neurons (MSNs) are hyper-responsive in obesity-prone individuals [34]. The NAc's interaction with predisposition factors and obesogenic environment may alter neurobehavioral plasticity in the NAc, which promotes weight gain and reduces weight loss 
in obesity-susceptible animals and people [34]. Recent work shows that cue-triggered motivation is enhanced in obesity-susceptible individuals after consuming "junk-food" [64]. Chronic and repeated exposure to food cues and specific diets may result in changes within the NAc, a part of the mesolimbic pathway that regulates food seeking behaviors [65]. The NAc's interaction with predisposition factors and an obesogenic environment may alter neurobehavioral plasticity in the NAc which may promote weight gain and reduce weight loss among obesity-susceptible animals and people [34].

Our second main finding, the predictive role of the frontoparietal network and NAc functional connectivity on BMI time 2 of female but not male children is very novel. An extensive body of research has previously shown that sex alters predictors of obesity and BMI change over time [66-70]. Socioeconomic status, mood regulation, and stress all differently correlate with BMI of males and females [66-70]. In many studies, obesity and BMI change have shown more associations in females than males [66-70]. This might be because females are more vulnerable to the risk factors of obesity, given their environmental situation, societal status, and coping mechanisms [66,68-76], or simply because obesity has a larger variance in females so our existing models can better explain BMI variation in females than males.

In our main analysis, we had follow-up BMI as the outcome and baseline BMI as a covariate. This is one of the two main approaches to analyze the repeated measure outcome only with two observations. Maria Glymour and others have discussed how controlling for baseline status of an outcome alters the interpretation of the results. We decided to control for baseline BMI when the outcome was time 2 BMI based on the causal diagram [77]. Still, to replicate the results in the same study, we ran a series of sensitivity analysis with BMI time 1 as the outcome. The interaction term between sex and NAc functional connectivity with the frontoparietal network on baseline BMI suggested that our results are robust.

\subsection{Implications}

Function of the NAc is believed to be modifiable through neuro-modulation [78]. NAc function has been modulated in both research and clinical settings [20,79-82]. Smoking cessation and weight loss programs, for example, have used modalities that leverage NAc modification [78]. Some programs that have stimulated the NAc have generated promising results in reducing food craving, as well as treatment of obesity-induced food addiction and other cue-related disorders [78]. Deep brain stimulation of the NAc is also a technique that can be implemented in therapies $[20,55,79-85]$.

\subsection{Limitations}

All studies, particularly those who are secondary analysis of some existing data, are limited in their design, methods, and measurements. NAc activity and high BMI may have bidirectional effects. However, we used a longitudinal design and established the longitudinal effect of baseline NAc function on children's BMI change over time. We only had a few confounders, and we did not have data on diet, food cues, obesogenic environment, mental health, emotion regulation, and food addiction. Finally, we should emphasize that in this study, our outcome was not a dichotomous variable of obesity but the continuous measure of BMI. As such, the result should not be interpreted as NAc function predicts obesity, but BMI value at time 2 (while BMI value at time 1 is controlled). That means, regardless of passing or not passing the threshold that we use to define obesity or overweight, NAc function predicts who develops a higher BMI over time.

\subsection{Future Research}

As the duration of follow up in our study was short, long-term longitudinal data are needed. Imaging studies on longitudinal association between the NAc, and behavioral development are needed. We only described a link between the NAc and BMI change. Future research should study the mechanism of the effects of the NAc on BMI change. Future work is needed on various social, behaviors, and brain mechanisms that can explain how baseline NAc function predicts future obesity, and how 
these paths may differ for various groups of American children. As the NAc is not only responsive to food but also other categories of rewards such as alcohol [65] and sex [86,87], future research should replicate this result for other cue-induced behaviors. Research should also investigate how food environment and past behaviors modulate the food cue-induced behaviors that regulate eating through a change in the NAc activity. The same can be relevant to tobacco, alcohol, illicit drugs, and sex. Changes in the NAc may regulate, promote, or inhibit tobacco, food, alcohol, and drug seeking behaviors [88-92]. At a public health level, knowledge regarding the role of the NAc on BMI and obesity may help us undo social, economic, and environmental inequalities in childhood obesity. It is important to study how social distribution of food cues generate inequalities and disparities in the burden of obesity in children. We need to study environmental risk factors that impact NAc function across populations of children. We need to know the societal and behavioral conditions that may alter the function of the NAc in children.

\section{Conclusions}

In this longitudinal epidemiological study, the NAc functional connectivity with the frontoparietal network was predictive of future BMI increase among female but not male American children. The NAc, the frontoparietal network, and their functional connectivity may be a part of the brain circuits involved in the development of obesity among female children.

Author Contributions: S.A.: conceptual design, data analysis, first draft, revision. S.B. and M.B.: contribution to the conceptual design and revision of the paper. All authors have read and agreed to the final version of the manuscript.

Funding: The ABCD Study is supported by the National Institutes of Health Grants [U01DA041022, U01DA041028, U01DA041048, U01DA041089, U01DA041106, U01DA041117, U01DA041120, U01DA041134, U01DA041148, U01DA041156, U01DA041174, U24DA041123, U24DA041147]. A full list of supporters is available at https: //abcdstudy.org/nih-collaborators. Assari is supported by the National Institutes of Health (NIH) grants CA201415 02, U54MD007598, DA035811-05, U54MD008149, D084526-03, and U54CA229974.

Acknowledgments: Data used in the preparation of this article were obtained from the Adolescent Brain Cognitive Development (ABCD) Study (https://abcdstudy.org), held in the NIMH Data Archive (NDA). This is a multisite, longitudinal study designed to recruit more than 10,000 children age 9-10 and follow them over 10 years into early adulthood. A listing of participating sites and a complete listing of the study investigators can be found at https://abcdstudy.org/principal-investigators.html. ABCD consortium investigators designed and implemented the study and/or provided data but did not necessarily participate in analysis or writing of this report. This manuscript reflects the views of the authors and may not reflect the opinions or views of the NIH or ABCD consortium investigators. The ABCD data repository grows and changes over time. The ABCD data used in this report came from DOI: 10.15154/1504041 which can be found at: https://nda.nih.gov/study.html?id=721.

Conflicts of Interest: The authors declare no conflict of interest.

\section{Appendix A}

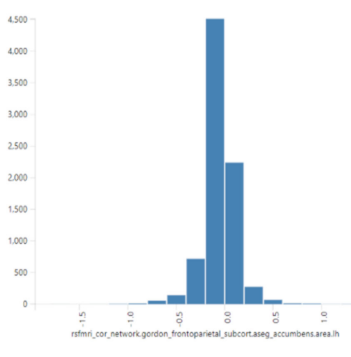

a

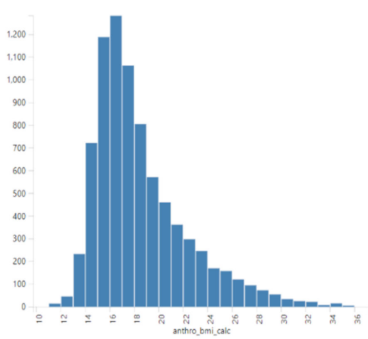

b

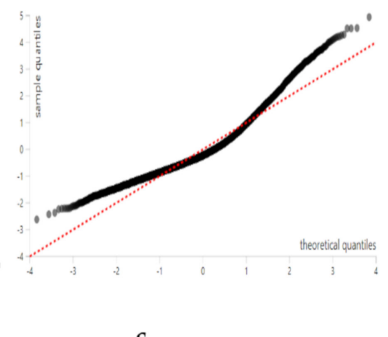

Figure A1. Assumptions for mixed-effects models for replication models. (a) histogram of the predictor (NAc functional connectivity with the frontoparietal network), (b) histogram of the outcome (baseline body mass index; BMI), (c) observed vs. theorized quartiles. 


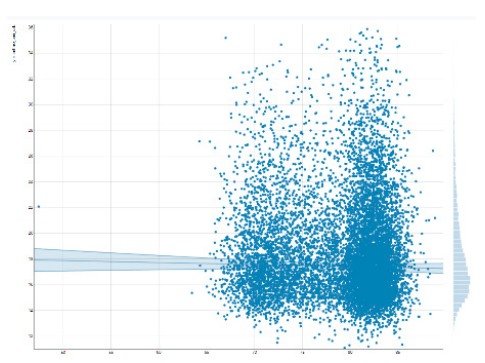

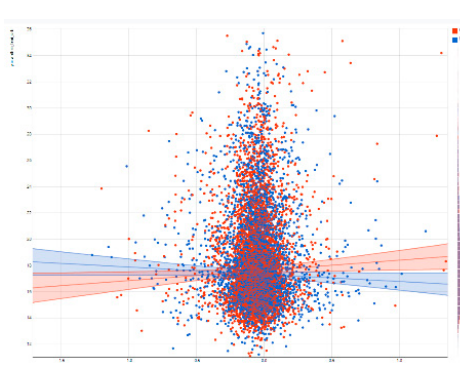

b

Figure A2. Regression coefficient of the effect of NAc functional connectivity with the frontoparietal network on BMI at baseline. (a) Overall association (blue), (b) association in females (red) and males (blue).

Table A1. Formula for replication models.

anthro_bmi_calc $\sim$ rsfmri_cor_network.gordon_frontoparietal_subcort.aseg_accumbens.area.lh + race.4level + sex + high.educ.bl + married.bl + age + household.income.bl + hisp + rsfmri_cor_network.gordon_frontoparietal_subcort.aseg_accumbens.area.lh * sex Random: $\sim(1 \mid$ abcd_site/rel_family_id $)$

Table A2. Distribution of study variables based on sex.

\begin{tabular}{|c|c|c|c|c|c|}
\hline & Level & All & F & $\mathbf{M}$ & $p$ \\
\hline $\mathrm{N}$ & & 10,184 & 3909 & 4168 & \\
\hline BMI time 1 (mean (SD)) & & $18.65(3.90)$ & $18.62(3.91)$ & $18.41(3.69)$ & 0.013 \\
\hline \multirow[t]{3}{*}{ Race (\%) } & White & $6802(66.8)$ & $2576(65.9)$ & $2859(68.6)$ & 0.051 \\
\hline & Asian & $218(2.1)$ & $93(2.4)$ & $78(1.9)$ & \\
\hline & Other/Mixed & $1708(16.8)$ & $670(17.1)$ & $665(16.0)$ & \\
\hline \multirow[t]{2}{*}{$\operatorname{Sex}(\%)$} & Female & $4860(47.7)$ & 3909 (100.0) & $0(0.0)$ & $<0.001$ \\
\hline & Male & $5324(52.3)$ & $0(0.0)$ & $4168(100.0)$ & \\
\hline \multirow[t]{3}{*}{ Parental Education (\%) } & $<$ High School Diploma & $369(3.6)$ & $144(3.7)$ & $117(2.8)$ & 0.142 \\
\hline & Bachelor & $2698(26.5)$ & $1061(27.1)$ & $1124(27.0)$ & \\
\hline & Postgraduate Degree & $3676(36.1)$ & $1413(36.1)$ & $1478(35.5)$ & \\
\hline \multirow[t]{2}{*}{ Family Married (\%) } & No & $3082(30.3)$ & $1190(30.4)$ & $1195(28.7)$ & 0.085 \\
\hline & Yes & $7102(69.7)$ & $2719(69.6)$ & $2973(71.3)$ & \\
\hline Age (mean (SD)) & & $118.96(7.47)$ & $118.93(7.47)$ & $119.24(7.53)$ & 0.060 \\
\hline \multirow[t]{3}{*}{ Household Income (\%) } & $(<50 \mathrm{~K})$ & $2900(28.5)$ & $1118(28.6)$ & $1157(27.8)$ & 0.508 \\
\hline & $(\geq 50 \mathrm{~K}$ and $<100 \mathrm{~K})$ & $2928(28.8)$ & $1145(29.3)$ & $1204(28.9)$ & \\
\hline & $(\geq 100 \mathrm{~K})$ & $4356(42.8)$ & $1646(42.1)$ & $1807(43.4)$ & \\
\hline
\end{tabular}

Table A3. Additive and multiplicative effects of NAc functional connectivity with the frontoparietal network on BMI at baseline based on sex.

\begin{tabular}{|c|c|c|c|c|c|}
\hline & b & SE & $t$ & $\mathrm{p}$ & sig \\
\hline Model 3 & & & & & \\
\hline NAc functional connectivity with the frontoparietal network & 0.77706 & 0.33632 & 2.31 & 0.020885 & * \\
\hline NAc functional connectivity with the frontoparietal network $\times$ Sex (Male) & -1.32806 & 0.44780 & -2.97 & 0.0030286 & ** \\
\hline
\end{tabular}




\section{References}

1. Dingess, P.M.; Darling, R.A.; Derman, R.C.; Wulff, S.S.; Hunter, M.L.; Ferrario, C.R.; Brown, T.E. Structural and Functional Plasticity within the Nucleus Accumbens and Prefrontal Cortex Associated with Time-Dependent Increases in Food Cue-Seeking Behavior. Neuropsychopharmacology 2017, 42, 2354-2364. [CrossRef]

2. Gugusheff, J.R.; Ong, Z.Y.; Muhlhausler, B.S. Naloxone treatment alters gene expression in the mesolimbic reward system in 'junk food' exposed offspring in a sex-specific manner but does not affect food preferences in adulthood. Physiol. Behav. 2014, 133, 14-21. [CrossRef]

3. Carr, K.D. Modulatory Effects of Food Restriction on Brain and Behavioral Effects of Abused Drugs. Curr. Pharm. Des. 2020, 26, 2363-2371. [CrossRef]

4. Olivo, D.; Caba, M.; Gonzalez-Lima, F.; Rodriguez-Landa, J.F.; Corona-Morales, A.A. Metabolic activation of amygdala, lateral septum and accumbens circuits during food anticipatory behavior. Behav. Brain. Res. 2017, 316, 261-270. [CrossRef]

5. Saul'skaya, N.B.; Mikhailova, M.O. Increased glutamate release into the intercellular space of the nucleus accumbens (N. accumbens) during substitution of food reinforcement with aversive or neutral stimuli. Neurosci. Behav. Physiol. 2004, 34, 109-113. [CrossRef]

6. Romani-Perez, M.; Lepinay, A.L.; Alonso, L.; Rincel, M.; Xia, L.; Fanet, H.; Caille, S.; Cador, M.; Laye, S.; Vancassel, S.; et al. Impact of perinatal exposure to high-fat diet and stress on responses to nutritional challenges, food-motivated behaviour and mesolimbic dopamine function. Int. J. Obes. (Lond) 2017, 41, 502-509. [CrossRef]

7. Salamone, J.D.; Mahan, K.; Rogers, S. Ventrolateral striatal dopamine depletions impair feeding and food handling in rats. Pharmacol. Biochem. Behav. 1993, 44, 605-610. [CrossRef]

8. Whishaw, I.Q.; Kornelsen, R.A. Two types of motivation revealed by ibotenic acid nucleus accumbens lesions: Dissociation of food carrying and hoarding and the role of primary and incentive motivation. Behav. Brain. Res. 1993, 55, 283-295. [CrossRef]

9. Kask, A.; Schioth, H.B. Tonic inhibition of food intake during inactive phase is reversed by the injection of the melanocortin receptor antagonist into the paraventricular nucleus of the hypothalamus and central amygdala of the rat. Brain. Res. 2000, 887, 460-464. [CrossRef]

10. Pan, Y.; Berman, Y.; Haberny, S.; Meller, E.; Carr, K.D. Synthesis, protein levels, activity, and phosphorylation state of tyrosine hydroxylase in mesoaccumbens and nigrostriatal dopamine pathways of chronically food-restricted rats. Brain. Res. 2006, 1122, 135-142. [CrossRef]

11. Pan, Y.; Siregar, E.; Carr, K.D. Striatal cell signaling in chronically food-restricted rats under basal conditions and in response to brief handling. Neurosci. Lett. 2006, 393, 243-248. [CrossRef]

12. Deshmukh, R.R.; Sharma, P.L. Stimulation of accumbens shell cannabinoid CB(1) receptors by noladin ether, a putative endocannabinoid, modulates food intake and dietary selection in rats. Pharmacol. Res. 2012, 66, 276-282. [CrossRef]

13. Nakazato, T. Striatal dopamine release in the rat during a cued lever-press task for food reward and the development of changes over time measured using high-speed voltammetry. Exp. Brain Res. 2005, 166, 137-146. [CrossRef]

14. Singer, B.F.; Bryan, M.A.; Popov, P.; Scarff, R.; Carter, C.; Wright, E.; Aragona, B.J.; Robinson, T.E. The sensory features of a food cue influence its ability to act as an incentive stimulus and evoke dopamine release in the nucleus accumbens core. Learn. Mem. 2016, 23, 595-606. [CrossRef]

15. Carr, K.D.; Cabeza de Vaca, S.; Sun, Y.; Chau, L.S. Reward-potentiating effects of D-1 dopamine receptor agonist and AMPAR GluR1 antagonist in nucleus accumbens shell and their modulation by food restriction. Psychopharmacology (Berl) 2009, 202, 731-743. [CrossRef]

16. Naef, L.; Moquin, L.; Gratton, A.; Walker, C.D. Reduced anticipatory dopamine responses to food in rats exposed to high fat during early development. Int. J. Obes. (Lond) 2013, 37, 885-888. [CrossRef]

17. Vollbrecht, P.J.; Nobile, C.W.; Chadderdon, A.M.; Jutkiewicz, E.M.; Ferrario, C.R. Pre-existing differences in motivation for food and sensitivity to cocaine-induced locomotion in obesity-prone rats. Physiol. Behav. 2015, 152, 151-160. [CrossRef]

18. Uribe-Cerda, S.; Morselli, E.; Perez-Leighton, C. Updates on the neurobiology of food reward and their relation to the obesogenic environment. Curr. Opin. Endocrinol. Diabetes Obes. 2018, 25, 292-297. [CrossRef] 
19. van de Giessen, E.; de Bruin, K.; la Fleur, S.E.; van den Brink, W.; Booij, J. Triple monoamine inhibitor tesofensine decreases food intake, body weight, and striatal dopamine D2/D3 receptor availability in diet-induced obese rats. Eur. Neuropsychopharmacol. 2012, 22, 290-299. [CrossRef]

20. Casquero-Veiga, M.; Garcia-Garcia, D.; Pascau, J.; Desco, M.; Soto-Montenegro, M.L. Stimulating the nucleus accumbens in obesity: A positron emission tomography study after deep brain stimulation in a rodent model. PLoS One 2018, 13, e0204740. [CrossRef]

21. Aitken, T.J.; Greenfield, V.Y.; Wassum, K.M. Nucleus accumbens core dopamine signaling tracks the need-based motivational value of food-paired cues. J. Neurochem. 2016, 136, 1026-1036. [CrossRef]

22. Tricomi, E.; Lempert, K.M. Value and probability coding in a feedback-based learning task utilizing food rewards. J Neurophysiol. 2015, 113, 4-13. [CrossRef]

23. Grottick, A.J.; Fletcher, P.J.; Higgins, G.A. Studies to investigate the role of 5-HT(2C) receptors on cocaineand food-maintained behavior. J. Pharmacol. Exp. Ther. 2000, 295, 1183-1191.

24. Gomez, A.A.; Shnitko, T.A.; Caref, K.L.; Nicola, S.M.; Robinson, D.L. Stimuli predicting high-calorie reward increase dopamine release and drive approach to food in the absence of homeostatic need. Nutr. Neurosci. 2020, 1-10. [CrossRef]

25. Derman, R.C.; Ferrario, C.R. Enhanced incentive motivation in obesity-prone rats is mediated by NAc core CP-AMPARs. Neuropharmacology 2018, 131, 326-336. [CrossRef]

26. Durst, M.; Konczol, K.; Balazsa, T.; Eyre, M.D.; Toth, Z.E. Reward-representing D1-type neurons in the medial shell of the accumbens nucleus regulate palatable food intake. Int. J. Obes. (Lond) 2019, 43, 917-927. [CrossRef]

27. Azzout-Marniche, D.; Chalvon-Demersay, T.; Pimentel, G.; Chaumontet, C.; Nadkarni, N.A.; Piedcoq, J.; Fromentin, G.; Tome, D.; Gaudichon, C.; Even, P.C. Obesity-prone high-fat-fed rats reduce caloric intake and adiposity and gain more fat-free mass when allowed to self-select protein from carbohydrate: Fat intake. Am. J. Physiol. Regul. Integr. Comp. Physiol. 2016, 310, R1169-76. [CrossRef]

28. Crespo, J.A.; Stockl, P.; Zorn, K.; Saria, A.; Zernig, G. Nucleus accumbens core acetylcholine is preferentially activated during acquisition of drug- vs food-reinforced behavior. Neuropsychopharmacology 2008, 33, 3213-3220. [CrossRef]

29. Oginsky, M.F.; Ferrario, C.R. Eating "junk food" has opposite effects on intrinsic excitability of nucleus accumbens core neurons in obesity-susceptible versus -resistant rats. J. Neurophysiol. 2019, 122, 1264-1273. [CrossRef]

30. Alsio, J.; Olszewski, P.K.; Norback, A.H.; Gunnarsson, Z.E.; Levine, A.S.; Pickering, C.; Schioth, H.B. Dopamine D1 receptor gene expression decreases in the nucleus accumbens upon long-term exposure to palatable food and differs depending on diet-induced obesity phenotype in rats. Neuroscience 2010, 171, 779-787. [CrossRef]

31. Brown, R.M.; Kupchik, Y.M.; Spencer, S.; Garcia-Keller, C.; Spanswick, D.C.; Lawrence, A.J.; Simonds, S.E.; Schwartz, D.J.; Jordan, K.A.; Jhou, T.C.; et al. Addiction-like Synaptic Impairments in Diet-Induced Obesity. Biol. Psychiatry 2017, 81, 797-806. [CrossRef]

32. Alonso-Caraballo, Y.; Fetterly, T.L.; Jorgensen, E.T.; Nieto, A.M.; Brown, T.E.; Ferrario, C.R. Sex specific effects of "junk-food" diet on calcium permeable AMPA receptors and silent synapses in the nucleus accumbens core. Neuropsychopharmacology 2020. [CrossRef]

33. Ong, Z.Y.; Muhlhausler, B.S. Maternal "junk-food" feeding of rat dams alters food choices and development of the mesolimbic reward pathway in the offspring. FASEB J. 2011, 25, 2167-2179. [CrossRef]

34. Oginsky, M.F.; Maust, J.D.; Corthell, J.T.; Ferrario, C.R. Enhanced cocaine-induced locomotor sensitization and intrinsic excitability of NAc medium spiny neurons in adult but not in adolescent rats susceptible to diet-induced obesity. Psychopharmacology (Berl.) 2016, 233, 773-784. [CrossRef]

35. Tan, Y.; Tan, J.; Deng, J.; Cui, W.; He, H.; Yang, F.; Deng, H.; Xiao, R.; Huang, Z.; Zhang, X.; et al. Alteration of Basal Ganglia and Right Frontoparietal Network in Early Drug-Naive Parkinson's Disease during Heat Pain Stimuli and Resting State. Front. Hum. Neurosci. 2015, 9, 467. [CrossRef]

36. Zoon, H.F.A.; de Bruijn, S.E.M.; Smeets, P.A.M.; de Graaf, C.; Janssen, I.M.C.; Schijns, W.; Aarts, E.O.; Jager, G.; Boesveldt, S. Altered neural responsivity to food cues in relation to food preferences, but not appetite-related hormone concentrations after RYGB-surgery. Behav. Brain. Res. 2018, 353, 194-202. [CrossRef] 
37. Krafft, C.E.; Schaeffer, D.J.; Schwarz, N.F.; Chi, L.; Weinberger, A.L.; Pierce, J.E.; Rodrigue, A.L.; Allison, J.D.; Yanasak, N.E.; Liu, T.; et al. Improved frontoparietal white matter integrity in overweight children is associated with attendance at an after-school exercise program. Dev. Neurosci. 2014, 36, 1-9. [CrossRef]

38. Kim, S.H.; Park, B.Y.; Byeon, K.; Park, H.; Kim, Y.; Eun, Y.M.; Chung, J.H. The effects of high-frequency repetitive transcranial magnetic stimulation on resting-state functional connectivity in obese adults. Diabetes Obes. Metab. 2019, 21, 1956-1966. [CrossRef]

39. Cerit, H.; Davidson, P.; Hye, T.; Moondra, P.; Haimovici, F.; Sogg, S.; Shikora, S.; Goldstein, J.M.; Evins, A.E.; Whitfield-Gabrieli, S.; et al. Resting-State Brain Connectivity Predicts Weight Loss and Cognitive Control of Eating Behavior After Vertical Sleeve Gastrectomy. Obesity (Silver Spring) 2019, 27, 1846-1855. [CrossRef]

40. Silvah, J.H.; Marchini, J.S.; Martires Lima, C.M.; Ferreira Nicoletti, C.; Alexandre Santos, L.; Nobuyuki Itikawa, E.; Trevisan, A.C.; Arriva Pitella, F.; Kato, M.; Iucif Junior, N.; et al. Regional cerebral blood flow at rest in obesity. Nutrition 2020, 79-80, 110888. [CrossRef]

41. Ding, Y.; Ji, G.; Li, G.; Zhang, W.; Hu, Y.; Liu, L.; Wang, Y.; Hu, C.; von Deneen, K.M.; Han, Y.; et al. Altered Interactions Among Resting-State Networks in Individuals with Obesity. Obesity (Silver Spring) 2020, 28, 601-608. [CrossRef]

42. Park, B.Y.; Lee, M.J.; Kim, M.; Kim, S.H.; Park, H. Structural and Functional Brain Connectivity Changes Between People With Abdominal and Non-abdominal Obesity and Their Association With Behaviors of Eating Disorders. Front. Neurosci. 2018, 12, 741. [CrossRef]

43. Lee, H.; Park, B.Y.; Byeon, K.; Won, J.H.; Kim, M.; Kim, S.H.; Park, H. Multivariate association between brain function and eating disorders using sparse canonical correlation analysis. PLoS ONE 2020, 15, e0237511. [CrossRef]

44. Pessoa, L.; Engelmann, J.B. Embedding reward signals into perception and cognition. Front. Neurosci. 2010, 4. [CrossRef]

45. Alcohol Research: Current Reviews Editorial Staff. NIH's Adolescent Brain Cognitive Development (ABCD) Study. Alcohol Res. 2018, 39, 97.

46. Casey, B.J.; Cannonier, T.; Conley, M.I.; Cohen, A.O.; Barch, D.M.; Heitzeg, M.M.; Soules, M.E.; Teslovich, T.; Dellarco, D.V.; Garavan, H.; et al. The Adolescent Brain Cognitive Development (ABCD) study: Imaging acquisition across 21 sites. Dev. Cogn. Neurosci. 2018, 32, 43-54. [CrossRef]

47. Karcher, N.R.; O’Brien, K.J.; Kandala, S.; Barch, D.M. Resting-State Functional Connectivity and Psychotic-like Experiences in Childhood: Results From the Adolescent Brain Cognitive Development Study. Biol. Psychiatry 2019, 86, 7-15. [CrossRef]

48. Lisdahl, K.M.; Sher, K.J.; Conway, K.P.; Gonzalez, R.; Feldstein Ewing, S.W.; Nixon, S.J.; Tapert, S.; Bartsch, H.; Goldstein, R.Z.; Heitzeg, M. Adolescent brain cognitive development (ABCD) study: Overview of substance use assessment methods. Dev. Cogn. Neurosci. 2018, 32, 80-96. [CrossRef]

49. Luciana, M.; Bjork, J.M.; Nagel, B.J.; Barch, D.M.; Gonzalez, R.; Nixon, S.J.; Banich, M.T. Adolescent neurocognitive development and impacts of substance use: Overview of the adolescent brain cognitive development (ABCD) baseline neurocognition battery. Dev. Cogn. Neurosci. 2018, 32, 67-79. [CrossRef]

50. Auchter, A.M.; Hernandez Mejia, M.; Heyser, C.J.; Shilling, P.D.; Jernigan, T.L.; Brown, S.A.; Tapert, S.F.; Dowling, G.J. A description of the $\mathrm{ABCD}$ organizational structure and communication framework. Dev. Cogn. Neurosci. 2018, 32, 8-15. [CrossRef]

51. Garavan, H.; Bartsch, H.; Conway, K.; Decastro, A.; Goldstein, R.Z.; Heeringa, S.; Jernigan, T.; Potter, A.; Thompson, W.; Zahs, D. Recruiting the ABCD sample: Design considerations and procedures. Dev. Cogn. Neurosci. 2018, 32, 16-22. [CrossRef]

52. Bjork, J.M.; Straub, L.K.; Provost, R.G.; Neale, M.C. The ABCD study of neurodevelopment: Identifying neurocircuit targets for prevention and treatment of adolescent substance abuse. Curr. Treat. Options Psychiatry 2017, 4, 196-209. [CrossRef]

53. Fair, D.A.; Miranda-Dominguez, O.; Snyder, A.Z.; Perrone, A.; Earl, E.A.; Van, A.N.; Koller, J.M.; Feczko, E.; Tisdall, M.D.; van der Kouwe, A.; et al. Correction of respiratory artifacts in MRI head motion estimates. Neuroimage 2020, 208, 116400. [CrossRef]

54. Hagler, D.J.; Hatton, S.; Cornejo, M.D.; Makowski, C.; Fair, D.A.; Dick, A.S.; Sutherland, M.T.; Casey, B.J.; Barch, D.M.; Harms, M.P.; et al. Image processing and analysis methods for the Adolescent Brain Cognitive Development Study. Neuroimage 2019, 202, 116091. [CrossRef] 
55. Oterdoom, D.L.M.; van Dijk, G.; Verhagen, M.H.P.; Jiawan, V.C.R.; Drost, G.; Emous, M.; van Beek, A.P.; van Dijk, J.M.C. Therapeutic potential of deep brain stimulation of the nucleus accumbens in morbid obesity. Neurosurg. Focus 2018, 45, E10. [CrossRef]

56. Shin, A.C.; Pistell, P.J.; Phifer, C.B.; Berthoud, H.R. Reversible suppression of food reward behavior by chronic mu-opioid receptor antagonism in the nucleus accumbens. Neuroscience 2010, 170, 580-588. [CrossRef]

57. Brown, H.D.; McCutcheon, J.E.; Cone, J.J.; Ragozzino, M.E.; Roitman, M.F. Primary food reward and reward-predictive stimuli evoke different patterns of phasic dopamine signaling throughout the striatum. Eur. J. Neurosci. 2011, 34, 1997-2006. [CrossRef]

58. Soria-Gomez, E.; Matias, I.; Rueda-Orozco, P.E.; Cisneros, M.; Petrosino, S.; Navarro, L.; Di Marzo, V.; Prospero-Garcia, O. Pharmacological enhancement of the endocannabinoid system in the nucleus accumbens shell stimulates food intake and increases c-Fos expression in the hypothalamus. Br. J. Pharmacol. 2007, 151, 1109-1116. [CrossRef]

59. Herisson, F.M.; Waas, J.R.; Fredriksson, R.; Schioth, H.B.; Levine, A.S.; Olszewski, P.K. Oxytocin Acting in the Nucleus Accumbens Core Decreases Food Intake. J. Neuroendocrinol. 2016, 28. [CrossRef]

60. Liu, X.; Gao, S.; Zhang, N.; Jin, T.; Sun, X.; Luan, X.; Xu, L.; Guo, F. The orexinergic neural pathway from the lateral hypothalamus to the nucleus accumbens and its regulation of palatable food intake. Neuropeptides 2020, 80, 102028. [CrossRef]

61. Saul'skaia, N.B.; Mikhailova, M.O. Th effect of D2-dopamine receptor blockade on glutamate release into extracellular space of Nucleus accumbens during food reinforcement. Zh. Vyssh. Nerv. Deiat. Im. I. P. Pavlova 2001, 51, 254-255.

62. Meena, H.; Nakhate, K.T.; Kokare, D.M.; Subhedar, N.K. GABAA receptors in nucleus accumbens shell mediate the hyperphagia and weight gain following haloperidol treatment in rats. Life Sci. 2009, 84, 156-163. [CrossRef]

63. Kalyanasundar, B.; Perez, C.I.; Luna, A.; Solorio, J.; Moreno, M.G.; Elias, D.; Simon, S.A.; Gutierrez, R. D1 and D2 antagonists reverse the effects of appetite suppressants on weight loss, food intake, locomotion, and rebalance spiking inhibition in the rat NAc shell. J. Neurophysiol. 2015, 114, 585-607. [CrossRef]

64. Oginsky, M.F.; Goforth, P.B.; Nobile, C.W.; Lopez-Santiago, L.F.; Ferrario, C.R. Eating 'Junk-Food' Produces Rapid and Long-Lasting Increases in NAc CP-AMPA Receptors: Implications for Enhanced Cue-Induced Motivation and Food Addiction. Neuropsychopharmacology 2016, 41, 2977-2986. [CrossRef]

65. Waeiss, R.A.; Knight, C.P.; Engleman, E.A.; Hauser, S.R.; Rodd, Z.A. Co-administration of ethanol and nicotine heightens sensitivity to ethanol reward within the nucleus accumbens (NAc) shell and increasing NAc shell BDNF is sufficient to enhance ethanol reward in naive Wistar rats. J. Neurochem. 2020, 152, 556-569. [CrossRef]

66. Assari, S. Additive Effects of Anxiety and Depression on Body Mass Index among Blacks: Role of Ethnicity and Gender. Int. Cardiovasc. Res. J. 2014, 8, 44-51.

67. Assari, S.; Lankarani, M.M. The Association Between Obesity and Weight Loss Intention Weaker Among Blacks and Men than Whites and Women. J. Racial Ethn. Health Disparities 2015, 2, 414-420. [CrossRef]

68. Assari, S.; Caldwell, C.H.; Zimmerman, M.A. Depressive Symptoms During Adolescence Predict Adulthood Obesity Among Black Females. J. Racial Ethn. Health Disparities 2018, 5, 774-781. [CrossRef]

69. Assari, S.; Moghani Lankarani, M.; Caldwell, C.H.; Zimmerman, M.A. Fear of Neighborhood Violence During Adolescence Predicts Development of Obesity a Decade Later: Gender Differences Among African Americans. Arch. Trauma Res. 2016, 5, e31475. [CrossRef]

70. Assari, S.; Caldwell, C.H. Low Family Support and Risk of Obesity among Black Youth: Role of Gender and Ethnicity. Children (Basel) 2017, 4, 36. [CrossRef]

71. Blostein, F.; Assari, S.; Caldwell, C.H. Gender and Ethnic Differences in the Association Between Body Image Dissatisfaction and Binge Eating Disorder among Blacks. J. Racial Ethn. Health Disparities 2017, 4, 529-538. [CrossRef]

72. Assari, S.; Caldwell, C.H. Gender and Ethnic Differences in the Association Between Obesity and Depression Among Black Adolescents. J Racial Ethn Health Disparities 2015, 2, 481-493. [CrossRef]

73. Assari, S.; Wisseh, C.; Bazargan, M. Obesity and Polypharmacy among African American Older Adults: Gender as the Moderator and Multimorbidity as the Mediator. Int. J. Environ. Res. Public Health 2019, 16, 2181. [CrossRef] 
74. Assari, S. Psychosocial Correlates of Body Mass Index in the United States: Intersection of Race, Gender and Age. Iran J. Psychiatry Behav. Sci. 2016, 10, e3458. [CrossRef]

75. Assari, S.; Nikahd, A.; Malekahmadi, M.R.; Lankarani, M.M.; Zamanian, H. Race by Gender Group Differences in the Protective Effects of Socioeconomic Factors Against Sustained Health Problems Across Five Domains. J. Racial Ethn. Health Disparities 2016. [CrossRef]

76. Carter, J.D.; Assari, S. Sustained Obesity and Depressive Symptoms over 6 Years: Race by Gender Differences in the Health and Retirement Study. Front. Aging Neurosci. 2016, 8, 312. [CrossRef]

77. Glymour, M.M.; Weuve, J.; Berkman, L.F.; Kawachi, I.; Robins, J.M. When is baseline adjustment useful in analyses of change? An example with education and cognitive change. Am. J. Epidemiol. 2005, 162, 267-278. [CrossRef]

78. Mantione, M.; van de Brink, W.; Schuurman, P.R.; Denys, D. Smoking cessation and weight loss after chronic deep brain stimulation of the nucleus accumbens: Therapeutic and research implications: Case report. Neurosurgery 2010, 66, E218. [CrossRef]

79. Cho, S.; Hachmann, J.T.; Balzekas, I.; In, M.H.; Andres-Beck, L.G.; Lee, K.H.; Min, H.K.; Jo, H.J. Resting-state functional connectivity modulates the BOLD activation induced by nucleus accumbens stimulation in the swine brain. Brain Behav. 2019, 9, e01431. [CrossRef]

80. Harat, M.; Rudas, M.; Zielinski, P.; Birska, J.; Sokal, P. Nucleus accumbens stimulation in pathological obesity. Neurol. Neurochir. Pol. 2016, 50, 207-210. [CrossRef]

81. Rezai, A.R.; Krishna, V.; Bogner, J.; Kramer, D.; Needleman, B.; Emerson, A.M.; Reider, C.; Fiore, G.J.; Corrigan, J.D. Letter: Feasibility of Nucleus Accumbens Deep Brain Stimulation for Morbid, Treatment-Refractory Obesity. Neurosurgery 2018, 82, E136-E137. [CrossRef]

82. Zhang, C.; Wei, N.L.; Wang, Y.; Wang, X.; Zhang, J.G.; Zhang, K. Deep brain stimulation of the nucleus accumbens shell induces anti-obesity effects in obese rats with alteration of dopamine neurotransmission. Neurosci. Lett. 2015, 589, 1-6. [CrossRef]

83. Ross, S.E.; Lehmann Levin, E.; Itoga, C.A.; Schoen, C.B.; Selmane, R.; Aldridge, J.W. Deep brain stimulation in the central nucleus of the amygdala decreases 'wanting' and 'liking' of food rewards. Eur. J. Neurosci. 2016, 44, 2431-2445. [CrossRef]

84. Ho, A.L.; Sussman, E.S.; Pendharkar, A.V.; Azagury, D.E.; Bohon, C.; Halpern, C.H. Deep brain stimulation for obesity: Rationale and approach to trial design. Neurosurg. Focus 2015, 38, E8. [CrossRef]

85. Dupre, D.A.; Tomycz, N.; Oh, M.Y.; Whiting, D. Deep brain stimulation for obesity: Past, present, and future targets. Neurosurg. Focus 2015, 38, E7. [CrossRef]

86. Demos, K.E.; Heatherton, T.F.; Kelley, W.M. Individual differences in nucleus accumbens activity to food and sexual images predict weight gain and sexual behavior. J. Neurosci. 2012, 32, 5549-5552. [CrossRef]

87. Welch, A.C.; Zhang, J.; Lyu, J.; McMurray, M.S.; Javitch, J.A.; Kellendonk, C.; Dulawa, S.C. Dopamine D2 receptor overexpression in the nucleus accumbens core induces robust weight loss during scheduled fasting selectively in female mice. Mol. Psychiatry 2019. [CrossRef]

88. Shalev, U.; Robarts, P.; Shaham, Y.; Morales, M. Selective induction of c-Fos immunoreactivity in the prelimbic cortex during reinstatement of heroin seeking induced by acute food deprivation in rats. Behav. Brain Res. 2003, 145, 79-88. [CrossRef]

89. Sadeghzadeh, F.; Babapour, V.; Haghparast, A. Role of dopamine D1-like receptor within the nucleus accumbens in acute food deprivation- and drug priming-induced reinstatement of morphine seeking in rats. Behav. Brain Res. 2015, 287, 172-181. [CrossRef]

90. Shalev, U.; Finnie, P.S.; Quinn, T.; Tobin, S.; Wahi, P. A role for corticotropin-releasing factor, but not corticosterone, in acute food-deprivation-induced reinstatement of heroin seeking in rats. Psychopharmacology (Berl.) 2006, 187, 376-384. [CrossRef] 
91. D'Cunha, T.M.; Daoud, E.; Rizzo, D.; Bishop, A.B.; Russo, M.; Mourra, G.; Hamel, L.; Sedki, F.; Shalev, U. Augmentation of Heroin Seeking Following Chronic Food Restriction in the Rat: Differential Role for Dopamine Transmission in the Nucleus Accumbens Shell and Core. Neuropsychopharmacology 2017, 42, 1136-1145. [CrossRef]

92. Tobin, S.; Sedki, F.; Abbas, Z.; Shalev, U. Antagonism of the dopamine D1-like receptor in mesocorticolimbic nuclei attenuates acute food deprivation-induced reinstatement of heroin seeking in rats. Eur. J. Neurosci. 2013, 37, 972-981. [CrossRef]

(C) 2020 by the authors. Licensee MDPI, Basel, Switzerland. This article is an open access article distributed under the terms and conditions of the Creative Commons Attribution (CC BY) license (http://creativecommons.org/licenses/by/4.0/). 